\title{
VISUALISASI AGAMA DI RUANG PUBLIK: KOMODIFIKASI, REPRODUKSI SIMBOL DAN MAKNANYA
}

\author{
Mujibur Rahman*
}

Abstract: Religion is an omnipresent entity that is present everywhere and anytime. Religion as a system of values and norms became the reference of his people in worship, thinking and acting. The presence of religion in public space can then be understood from this character or trait. Religious presence is not always of value and doctrine or way of life, but is also present through material and visual forms, propagated through the media and all existing instruments. Religion, especially after the invention of the printing press and the internet technology revolution, became a new phenomenon that was represented in various forms. Religious commodities, religious commodities, and religious visualizations in today's technological era are a necara phenomenon. This paper wants to review the new phenomenon of religious visualization that now must be realized began to be an option to be displayed in the public space through what is referred to as visual merchandising. Visualization of religion here can not be separated from the context of religious commodification that has been reviewed by intellectuals and previous research, where religion is regarded as part of a market commodity that can be used as a tool to bring profit. Further religious visualization is not just a commodification, but a new style of religious adherents to affirm the existence of this religion. This paper finds that the visual of the religion that many appear in the public space, whether it is realized or not has become an interesting new phenomenon to be discussed.

Keywords: Visualization of religion, commodification of religion, visual merchandising, public space

\footnotetext{
* Dosen Prodi PAI Fakultas Tarbiyah INZAH Genggong Kraksaan Probolinggo
} 


\section{A. Pendahuluan}

Sejak ditemukanya mesin cetak (printing press) pada tahun 1400an, kegiatan pemasaran berkembang sedemikian rupa, dan kegiatan periklanan (advertising) lahir untuk pertama kali. Periklanan pada abad 15 tersebut telah merevolusi cara orang dalam berjualan, yaitu dengan menggambarkan atau memvisualkan produk-produk yang ingin dijual di selembar kertas, dan meletakkannya di tempat-tempat ramai. Periklanan zaman awal cukup sederhana, digunakan untuk menjual buku paling populer saat itu; Bible. Iklannya sangat singkat, padat dan jelas: "Kami punya Bible, di sini Anda dapat membelinya, dan ini harga yang harus Anda bayarkan." Model penjualan semacam ini masih kita kenal sampai hari ini, yakni melalui baliho, spanduk, poster dan semacamnya, dimana para ahli menyebut media ini sebagai media luar ruang. (Einstein, 2008: 67)

Ditemukannya mesin cetak juga mengubah cara orang dalam menulis, dari awalnya menulis di tulang, daun lontar, kulit, bahkan dinding goa, kemudian beralih di medium kertas. Dari medium kertas kita menyaksikan peradaban yang luar biasa, yang sampai hari ini tidak bisa digantikan oleh teknologi canggih seperti gadget sekalipun. Dengan ditemukannya mesin cetak, orang tidak perlu lagi berkeliling dan berteriak untuk mengumumkan sesuatu, cukup menempelkan dan memvisualkan apa yang dimaksudkan, dan menempelkannya di tempat-tempat ramai. Pengumuman atau gambar tersebut akan berbicara sendiri kepada khalayak.

Fenomena tersebut masih bisa dijumpai di zaman kita dewasa ini. Gambar visual yang tercetak di baliho, spanduk, poster dan aneka jenis media luar ruang yang lahir dari revolusi mesin cetak abad 15 silam masih menyesaki pelosok kota kita. Tidak terhitung produk-produk yang divisualkan melalui media luar ruang ini, mulai dari produk makanan, rumah, mobil, hingga wajah para tokoh partai atau tokoh organisasi tertentu. Tidak berhenti di situ, agama ternyata juga tidak luput dari obyek visualisasi di media luar ruang ini. Di sinilah tulisan ini ingin memfokuskan diri, yakni bagaimana agama divisualkan di ruang publik, melalui media luar ruang, dan terus diproduksi keberadaannya untuk menyampaikan pesan atau agenda tertentu. Apa agenda di baliknya, dan bagaimana proses itu berlangsung. 


\section{B. Pembahasan}

\section{Visual Agama di Ruang Publik}

Penetrasi simbol-simbol agama, khususnya secara visual, semakin menyebar di ruang-ruang publik, dengan repitisi atau pengulangan yang semakin intens. Simbol-simbol itu memapar khalayak lewat visualisasi. Di era new media, simbol-simbol agama dalam berbagai bentuknya, terutama yang bersifat visual sebagaimana karakteristik media di era web 2.0, disebarkan untuk menyampaikan suatu agenda atau pesan tertentu. Media televisi, internet, film, yang merupakan media elektronik, maupun koran, majalah, buku atau sticker, yang merupakan media cetak, serta baliho, poster serta spanduk, yang nota bene merupakan media luar-ruang, secara masif menampilkan simbol-simbol visual tanpa henti di ruang publik.

Ruang publik (public sphere) di sini dipahami sebagai sebuah ruang kontestasi, sebuah ruang dimana semua orang memiliki kesempatan yang sama untuk berkomunikasi, tanpa pembatasan (restricton) dan tanpa melihat status sosial. Ruang publik juga dipahami sebagai ruang antara yang pribadi (private) dan negara (state). Sebuah "forum" atau "arena" dimana publik bisa "bersuara."

Penetrasi visual agama ini bisa diliihat misalnya di sudut-sudut kota, di pinggir jalan, dinding rumah, di jembatan, di pepohonan bahkan di tiang listrik sekalipun. Isinya beraneka rupa, mulai dari produk-produk ekonomi, sampai muka-muka para caleg, tokoh organisasi atau partai tertentu, dan termasuk juga gambar-gambar tentang agama. Visualisasi agama di sini misalnya ajakan untuk menggunakan barang-jasa yang bernafaskan agama, klaim terhadap wilayah tertentu sebagai wilayah religius, maupun sekedar klaim bahwa "kami beragama tertentu," atau selalu mengedepankan agama tertentu sebagai visi.

Penting kiranya kita menganalisis makna di balik munculnya visualisasi tersebut dalam ruang publik. Makna tersebut bukan sekedar mengungkap pesan yang disampaikan lewat visual, tetapi makna dari adanya pesan visual itu sendiri, dan mengapa pesan-pesan visual agama itu menjadi pilihan untuk disebarkan. Dalam hal ini penulis ingin membatasi

1 Koller, Andreas. 2010. The Public Sphere and Comparative Historical Research: An Introduction. Social Science History Vol. 34, No. 3, In Honor of Charles Tilly. Hal: 263-264) 
kajian kepada simbol-simbol agama Islam, yang menjadi agama mayoritas di Indonesia, dan bagaimana mereka direpresentasikan melalui media luar ruang seperti baliho, spanduk atupun poster. Khusus dalam penelitian ini penulis mengambil setting lokasi di Yogyakarta, kota yang kerap disebut sebagai city of tolerance karena banyaknya suku, etnis, agama dan kultur yang hidup di kota ini. Di sejumlah sudut-sudut Kota Yogyakarta, tidak sulit menemukan gambar visual yang berisikan pesan-pesan agama tertentu. Pesan-pesan ini diproduksi sedemikian rupa dan ditempatkan di area-area strategis agar bisa dilihat orang banyak.

\section{Gambar I: Monumen Kampung Ramadhan di Jogokarian, Mantrijeron, Kota Yogyakarta}

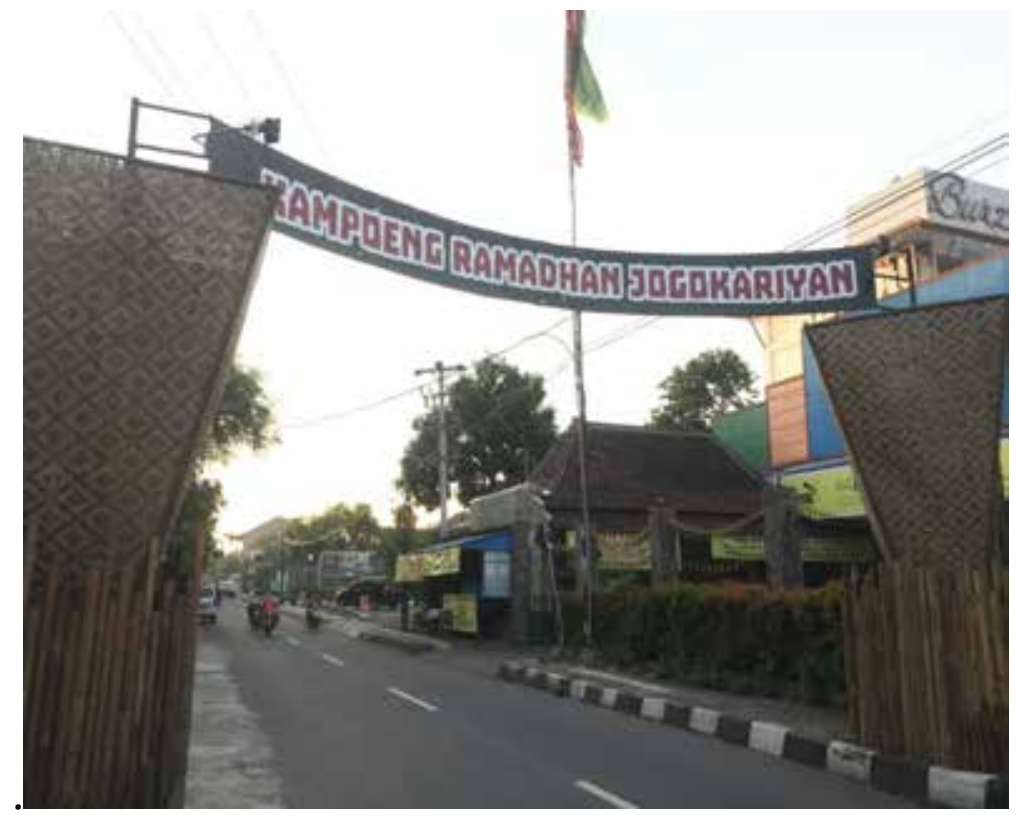

Sumber: Doc. Penulis.

Salah satu yang penulis temukan adalah monumen "kampung Ramadhan Jogokarian”, terletak di Kec. Mantrijeron, Kota Yogyakarta, seperti dalam gambar di atas. Monumen ini sifatnya permanen, sehingga sekalipun di luar bulan ramadhan monumen tersebut tetap berdiri, berbeda dengan spanduk yang sifatnya relatif tidak permanen. Monumen itu menampilkan pesan bahwa Jogokarian, sebuah kampung di Kelurahan Mantrijeron, Kec. 
Mantrijeron, Kota Yogyakarta, adalah kampung ramadhan, kampungnya orang Muslim, atau kampung yang bernuansa religius. Jika di daerah-daerah lain komodifikasi agama banyak ditemukan selama bulan ramadhan, status kampung ramadhan Jogokarian tetap ditegaskan lewat ornamen-visual sekalipun tidak dalam suasana bulan ramadhan.

Visualisasi agama di Jogokarian tidak hanya terepresentasi dalam bentuk ornamen saja, tetapi juga dalam praktik ekonomi-bisnis di dalamnya, yang semakin melegitimasi kampung ini sebagai kampung religius. Contoh bisa dilihat digambar dibawah ini:

Gambar 2: Salon Muslimah di Kampung Ramadhan Jogokarian.

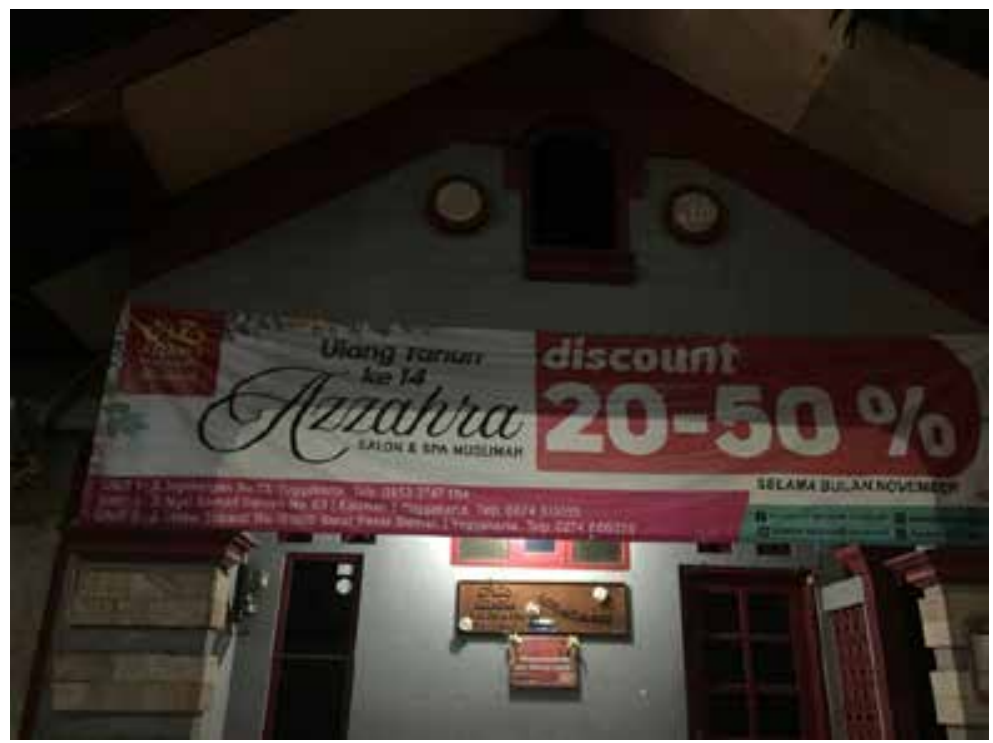

Sumber: Doc. Penulis.

Dalam gambar di atas kita bisa melihat praktik ekonomi masyarakat Jogokarian tidak lepas dari kerangka agama, sehingga muncullah salon dan spa muslimah Azzahra, yang seolah senafas-seirama dengan brand Kampung Jogokarian sebagai kampung ramadhan. Pilihan mendirikan salon dan spa muslimah di sini tidak lahir dari ruang pikir kosong, tetapi erat kaitannya dengan konteks yang mengitarinya. Klaim kampung ramadhan tentu tidak sekedar motto belaka, namun menjadi penegasan dari adanya suatu fenomena tertentu yang mendukung klaim tersebut, seperti berdirinya salon muslimah di atas. 
Selain itu, masih banyak visual agama di tempat lain di Yogyakarta, seperti misalnya di Prayan Kulon, Condong Catur, Depok, Sleman, Yogyakarta, tepatnya di Kampus Bina Insan Mulia Yogyakarta.

Gambar 3: Poster iklan kampus Bina Insan Mulia, Yogyakarta.
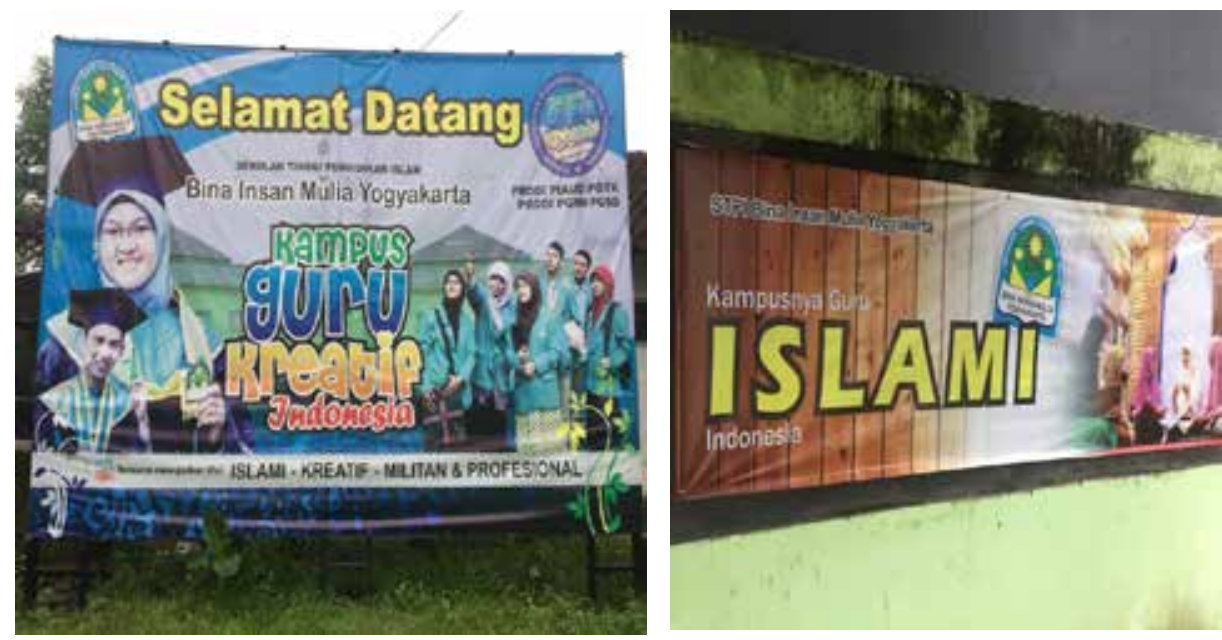

Sumber: Doc. Penulis

Gambar di atas memperlihatkan bagaimana agama ditampilkan dalam sebuah poster institusi pendidikan atau poster kampus. Di sini kita bisa melihat agama tampil dalam kerangka atau konteks yang berbeda-beda, tetapi tetap dalam sebuah ruang simbolik berupa visualisasi di tengahtengah ruang publik. Kampus di sini adalah lingkungan yang berbeda dengan lingkungan masyarakat, kampus adalah ruang pendidikan, yang sebagian besar aktifitasnya berputar dalam bidang pengajaran dan pembelajaran yang menitikberatkan pada proses perkembangan keilmuan, dengan output yang jelas, yakni membekali peseta didiknya dengan kompetensi sesuai bidang yang dipilih. Keberadaan dan reproduksi visual ini akan terus ada, karena itulah pemaknaan dan penafsiran tentangnya menjadi hal yang tidak bisa ditinggalkan.

\section{Visual Merchandising of Religion}

Visualisasi menurut Kamus Bahasa Indonesia adalah pemberian gambar tentang sesuatu, atau penjelasan tentang sesuatu dengan bantuan 
gambar agar lebih mudah dilihat. (Kamu Bahasa Indonesia: 1801). Pemberian gambar ini berbagai macam jenisnya, baik digital, yang dewasa ini menjadi trend media baru, atau pemberian gambar konvensional seperti baliho, poster, lukisan, foto, dan lain sebagainya. Visualisasi digunakan untuk memperkenalkan produk-produk atau komoditi ekonomi untuk memperoleh public awareness, dimana dalam istilah pemasaran disebut dengan konsep visual merchandising, yang diartikan sebagai aktivitas penataan (presentasi) produk agar konsumen dapat melihat merek, kemasan, serta harga secara jelas, untuk menarik minat pembeli. Merchandising sendiri diartikan sebagai barang dagangan, dan visualisasi diartikan sebagai aktifitas untuk mempresentasikannya di depan khalayak melalui gambar atau bahkan suara dan gambar (video). Merchandising juga berlaku bagi barang yang sebenarnya bukan barang dagangan, seperti wajah para caleg, tokoh partai, wajah calon presiden, dan sebagainya, tetapi dianggap atau diperlakukan layaknya barang dagangan, bukan agar masyarakat membeli, tetapi agar masyarakat memilih. ${ }^{2}$

Dalam visualisasi terdapat tujuan khusus untuk mengenalkan, memberitahu, menarik perhatian, mempromosikan, sehingga pada akhirnya menuntut khalayak untuk membeli, memilih, menonton, mengoleksi, mendatangi dan seterusnya, barang-barang yang divisualkan. Pada intinya, setiap visualisasi bertujuan untuk meningkatkan daya jual sebuah produk, atau jika itu kampanye politik, untuk meningkatkan keterpilihan partai maupun tokoh tertentu. Dan hal tersebut menjadi hal yang lumrah dalam dunia bisnis dan ekonomi-politik. Pertanyaan kemudian muncul, bagaimana jika yang divisualkan bukan produkproduk ekonomi ataupun politik, bukan barang dagangan, bukan caleg, tetapi agama, yang terepresentasi dalam nilai-nilainya, sehingga tidak menuntut orang untuk membeli barang yang divisualkan itu? Apakah logika visualisasi, yang selalu menuntut khalayak untuk membeli, memilih, melaksanakan, mendatangi, atau mendukung, masih bekerja dalam taraf ini? Apa makna yang bisa digali dari praktik visualisasi agama ini? Ataukah dalam visualisasi tersebut terdapat upaya untuk menjual agama, dalam arti menjadikan agama sebagai komoditi yang bisa diperjual belikan sehingga bisa menghadirkan keuntungan ekonomi

${ }^{2}$ Sutiono, Rudy Jusup. 2009. Visual Merchandising Attraction. Jakarta: Gramedia Pustaka Utama. hal: 32-33. 
maupun politik, yang dikenal dengan komodifikasi agama? Ataukah ada alternatif pemaknaan lain yang luput dari analisa kita selama ini?

Analisis paling rasional untuk memaknai dan menafsirkan fenomena visual agama di runag publik ini adalah dengan meletakkan agama sebagai barang komoditas, yang divisualkan dan diberi nilai layaknya barang-barang komoditas lainnya di pasar. Dalam logika ini, agama ditampilkan dengan "cara baru", walaupun sebenarnya adalah "barang lama”. Visualisasi adalah produk yang lahir dari kapitalisme, dan agama sudah ada sebelum itu. Ketika agama menjadi sasaran atau obyek visualisasi, sulit untuk menolak kecendrungan bahwa agama telah jatuh dalam tataran komodifikasi, dimana dalam hal ini komodifikasi visual. Komodifikasi agama sendiri memang tidak terbatas kepada komersialisasi belaka, tetapi lebih dari itu ideologisasi dalam praktik komersialisasi itu sendiri. Komodifikasi agama mengandung makna adanya komoditisasi agama, atau ideologisasi komoditas, dimana kita sebenarnya menjual agama melalui produk, atau menjual produk tertentu dengan memberikan nilai agama di dalamnya. ${ }^{3}$

Di Jogokarian, istilah "Kampung Ramadhan” tidak hanya jargon semata, tetapi dipraktikkan melalui usaha kreatif warga masyarakatnya yang menjual aneka macam produk seperti makanan, jajanan, barang dan jasa seperti salon, dan tentu saja kegiatan-kegiatan di sekitar Masjid Jogokarian yang menjadi pusat aktifitasnya. Di sini kita tidak selalu melihat agama, tetapi sebuah perputaran bisnis dan ekonomi. Agama di sini berarti roda perputaran ekonomi yang hidup baik saat bulan Ramadhan maupun di luar bulan Ramadhan itu sendiri. Ketika bulan Ramadhan tiba, sepanjang jalan di kampung Jogokarian penuh dengan penjual-penjual makanan, aneka jajanan, kudapan, minuman, dan kuekue untuk orang yang berbuka puasa. Ada juga orang yang berjualan busana muslim, mulai dari sarung, songkok, baju koko atau baju takwa, suvenir-suvenir Islami, bahkan salon dan spa untuk muslimah.

Di sini Islam, yang terepresentasi dalam praktik ibadah seperti puasa dan tempat ibadah, yakni masjid, dikemas dan ditawarkan kepada khalayak banyak dengan sebuah event besar berupa "Kampung

${ }^{3}$ Hasan, Noor Haidi. 2016. Islam di Kota-kota Menengah di Indonesia: Kelas Menengah, Gaya Hidup, dan Demokrasi. Editor: Gery Klinken dan Ward Berenschot. E. K. M. Masinambow. Jakarta: Yayasan Obor Indonesia.hal: 230. 
Ramadhan” Jogokarian. Kampung Ramadhan ini direproduksi terusmenerus dalam wacana dan sistem kesadaran penganutnya, tidak hanya selama bulan ramadhan, tetapi sepanjang tahun, selamanya. Di sini citra kampung ramdhan melekat bukan selama bulan ramadhan saja, tetapi selamanya.

Karena itulah monumen yang berdiri saat kita memasuki wilayah kampung Jogokarian dibuat, untuk menjaga ingatan khalayak, melalui visualisasi monumen tersebut, bahwa Jogokarianlah kampung Ramadhan di Yogyakarta, tidak ada di tempat lain hal semacam ini. Sekalipun di tempat lain kegiatan ramadhan tetap berlangsung, tetapi tidak akan menjadi kampung Ramadhan sebagaimana Jogokarian memilikinya. Ini persoalan bukan karena kampung yang lain tidak benar-benar khusyuk melakukan kegiatan ramadhan, tetapi persoalan bagaimana memberi nilai kepada aktifitas itu dan mereproduksinya dalam visual-visual di ruang publik.

Dalam visualisasi yang kedua, Bina Insan Mulia, agama divisualkan sedemikian rupa di poster-poster kampus agar khalayak sadar bahwa dalam kampus yang bersangkutan tidak sekedar kampus biasa yang mengajarkan ilmu-ilmu sesuai target pembelajaran dan visi keilmuan yang ingin dicapai, tetapi bermakna lebih dalam lagi sebagai kampus yang memiliki agama. Dengan melihat poster Kampus Bina Insan Mulia, khalayak akan paham bahwa kampus ini memiliki agama tertentu, yakni Islam. Sampai di sini syarat-syarat komodifikasi sudah terpenuhi, yaitu pertama, memiliki nilai agama, dan kedua, mengejar profit. ${ }^{4}$

Syarat komodifikasi pertama ialah gagasan atau barang yang ditawarkan memiliki nilai agama. Visual dalam poster itu jelas mendukung terhadap klaim ini. Nama "Bina Insan Mulia" tidak merujuk kepada agama tertentu, tetapi visual kalimat "Kampusnya Guru Islami Indonesia" dan "Bersama Mewujudkan Visi Islami, Kreatif, Militan dan Profosional" tidak bisa ditolak merupakan sebentuk ideologisasi yang mengandung muatan komodifikasi. Kedua, komodifikasi selalu memiliki motif mencari laba. Jelas untuk melaksanakan kegiatan pengajaran dan pembelajaran di perguruan tinggi seperti Bina Insan Mulia dibutuhkan biaya operasional, baik untuk fasilitas pengajaran dan biaya untuk mengajar tenaga pendidiknya. Agar tercapai kampus tersebut harus mengejar batasan

${ }^{4}$ (Marbun \& Pratama, 2016:117). 
finansial tertentu agar semua kegiatan terlaksana dengan lancar, dan itu adalah profit.

Praktik visual agama yang digunakan dalam kasus-kasus di atas adalah sebentuk visual merchandising of religion, dimana agama diperlakukan sebagaimana barang-barang dagangan. Tidak hanya itu, agama ditampilkan di ruang publik dengan motif tertentu dan terjadilah ajang komodifikasi. Dalam konteks visual, sejak ditemukannya mesin cetak pertama kali pada abad 14 silam, visual merchandising selalu memiliki motif yang mengarah kepada kampanye untuk membuat khalayak merespon, baik dengan respon membeli atau mengkonsumsi dalam ekonomi, respon memilih atau mendukung dalam politik, ataupun respon lainnya seperti mendatangi atau memberikan legetimasi. Tidak ada logika kosong dalam proses visualisasi.

Lebih jauh lagi, monumen kampung ramadhan, spanduk salon muslimah, dan poster salah satu kampus di Yogyakarta, yang didesain sedemikian rupa sebagai medium untuk menyampaikan pesan tertentu, sebenarnya tidak lagi ingin menyampaikan sesuatu di luar dirinya, misalnya sebuah aktifitas Ramadhan, tetapi itulah pesannya sendiri. Di sinilah teori medium is the message berlaku. Marshall McLuhan (1911-1980) menegaskan, media yang seharunya menyampaikan pesan, katakanlah dari komunikator kepada komunikan, keluar dari fungsinya dan menjadi pesan itu sendiri. Media tidak lagi membawa pesan, tetapi media itulah pesannya. Ornamen kampung ramadhan bukan ingin sekedar menyampaikan "sesuatu" yang terjadi di Jogokarian, tetapi oranmen itulah "sesuatu" itu sendiri. Ornamen yang dipakai, visual yang diciptakan, dan media yang dipakai untuk menyampaikan pesan, justru itulah pesannya. Melalui apa kata-kata itu dituliskan, lebih bermakna bila dibandingkan dengan kata-kata itu sendiri. Melalui apa sebuah gambar divisualkan, lebih bermakna daripada realitas yand diwakili oleh gambar itu sendiri. Melalui apa ide disampaikan, lebih bermakna dariapda ide itu sendiri. Dan melalui apa pesa-pesan disampaikan, lebih bermakna dari pesan itu sendiri. $^{5}$ 


\section{Agama Visual: Dimensi Baru Agama?}

Oleh para cendikiawan, agama disebut sebagai entitas omnipresent, karena senantiasa hadir dimana-mana dan kapan saja. Tidak ada ruang dan waktu dimana agama tidak hadir, bahkan saat kita sedang sendirian. Begitupun tidak ada sektor, bidang, dan dimensi kehidupan dimana agama absen. Dalam teknologi, ilmu pengetahuan, filsafat, apalagi etika dan nilai-nilai budaya, agama selalu hadir menegaskan status ultimate-nya sebagai sumber kebenaran serta pengatur kehidupan manusia. ${ }^{6}$

Kehadiran ini adalah kehadiran yang inheren, kehadiran yang bersifat nilai, spirit, dan keyakinan, bukan kehadiran tertulis apalagi kehadiran visual. Nilai-nilai agama yang substansial melekat dalam diri pribadi pemeluknya, bukan melekat pada simbol-simbol agama yang merujuk kepada sesuatu yang lain, atau ajaran tertulis dalam kitab suci, maupun dalam tempat-tempat keagamaan seperti masjid. Kehadiaran agama itu adalah dalam sistem nilai yang dianut bersama oleh pemeluknya.

Menjadi menarik kemudian melihat keserba-hadiran agama ini dalasm kaitannya dengan visual agama yang ditampilkan di ruang-ruang publik. Representasi agama yang kita sadari sejak dulu, misalnya melalui ritual atau ibadah seperti shalat, haji, kegiatan pengajian, atau melalui representasi material seperti tempat ibadah, ajaran yang terwujud dalam kitab suci dan kitab-kitab turunannya, atau representasi behavioral seperti ucapan dan tingkah laku berbagai penganutnya, kini semakin kompleks lagi dengan hadirnya realitas visual agama. Jadi selain agama tampil sebagai sebuah ritual, material, dan behavioral, ternyata di era modern seperti saat ini agama juga tampil dalam bentuk visual.

Sebelum membahas agama ritual, material, behavioral dan juga visual, Bapak Antropologi Indonesia, ${ }^{7}$ membagi aspek-aspek agama dalam empat aspek yang kurang lebih sama, kecuali dalam aspek visual ini. Keempat aspek agama menurut Koentjaraningrat adalah sebagai berikut:

a. Emosi keagamaan. Yakni aspek esoteris dalam agama yang menyebabkan manusia bersifat religius. Dalam aspek ini terkandung akidah atau keyakinan terhadap Dzat Yang Maha Tinggi, sebuah realitas ultimate yang disebut Tuhan.

${ }^{6}$ Sugiharto, Bambang. 2000. Wajah Baru Etika dan Agama. Yogyakarta. Kanisius. Hal: 11.

7 Koentjaraningrat (1923-1999) 
b. Sistem keyakinan yang mengandung segala keyakinan serta bayangan manusia tentang sifat-sifat Tuhan, tentang wujud alam gaib, serta segala hal, norma dan ajaran religi yang bersangkutan. Dalam taraf ini terdapat sistem kepercayaan atau ajaran yang membedakan agama yang satu dengan agama yang lain.

c. Sistem ritual atau upacara yang merupakan usaha manusia untuk mencari hubungan dengan Tuhan, dewa-dewa, atau mahluk halus yang mendiami alam ghaib.

d. Umat atau kesatuan sosial yang menganut sistem keyakinan tentang sifat Tuhan, wujud alam gaib, nilai atau norma yang sama. ${ }^{8}$

Sementara menurut ahli agama Skotlandia, ${ }^{9}$ ada tujuh dimensi dalam setiap agama. Dimensi pertama adalah dimensi praktis-ritual sebagaimana tampak dalam upacara suci, perayaan hari besar, pantang dan puasa untuk pertobatan, doa, kebaktian dan sebagaimnya. Dimensi kedua, emosionalekspresional menunjuk para perasaan dan pengalaman para penganutnya, yang bervariasi. Peristiwa-peristiwa khusus, gaib atau luar biasa yang dialami para penganutnya menimbulkan berbagai macam kegembiraan atau kekaguman. Topik yang penting dalam dimensi kedua ini adalah soal pengalaman mistik-spiritual, dimana penganutnya merasakan kekuatan yang erat dengan ilahi. Dimensi naratif atau mistik menjadi dimensi ketiga, yang menyajikan kisah atau cerita-cerita suci untuk direnungkan dan dicontoh, karena di situ ditampilkan tokoh-tokoh suci, pahlawan ataupun kejadian-kejadian yang penting dalam pembentukan agama yang bersangkutan. Dimensi keempat adalah dimensi filosofis-doktrinal, yakni aspek pemikiran rasional, argumentatif dan penalaran terutama menyangkut ajaran-ajaran agama, pendasaran hidup dan pengertian yang dianut agama itu sendiri.

Dimensi kelima adalah dimensi legal-etis, yang menyangkut tata-tertib hidup dalam agama itu, pengaturan bersama dengan norma-norma dan peraturan, tidak jarang disertai pula dengan sistem penghukuman kalau terjadi pelanggaran. Dimensi keenam yaitu sosial-institusional mengatur kehidupan bersama menyangkut keorganisasian dan kepemimpinan.

8 Simanjuntak, Bungaran Antonius. 2016. Tradisi, Agama, Dan Akseptasi Modernisasi Pada Masyarakat Pedesaan Jawa. Jakarta. Yayasan Obor. Hal: 99.

9 Ninian Smart (1927-2001), 
Ketujuh dimensi material, sebuah dimensi yang menyangkut barangbarang atau alat-alat yang digunakan untuk pemujaan atau pelaksanaan kehidupan agama itu sendiri. Termasuk di sini bangunan-bangunan tempat ibadah. ${ }^{10}$

Seluruh aspek dalam agama yang disebutkan diatas, baik dari Koentjaraningrat maupun Ninian Smart tampak sudah cukup komprehensif mencakup semua dimensi agama. Tetapi seiring kemajuan teknologi dan perkembangan gaya hidup umatnya, batasan aspek-aspek itu terasa tidak memadai lagi. Globalisasi, teknologi, media dan mobilitas telah mengubah seluruh cara pandang manusia terhadap kebudayaan, begitu pula cara pandang terhadap agama. Batas-batas kebudayaan, yang dulu dipuja sebagai "milik kita", "milik mereka", kini telah melebur menjadi sebuah unifikasi universal yang disebut deteritorialisasi. ${ }^{11}$

Berangkat dari tesis tersebut perlulah di sini diulas aspek lain dari agama yang selama ini belum terlalu diperhatikan, yakni agama visual. Mengikuti alur berpikir Koentjaraningrat dan Ninian Smart, penulis disini membagi agama dalam beberapa aspek, yaitu ritual, material, behaviroral, dan visual. Yang ketiga pertama sudah dicakup dalam pembagian aspek di atas, sementara yang terakhir, yaitu aspek visual, merupakan aspek baru yang kita temukan kalau kita melihat fenomena agama dewasa ini.

Aspek ritual dalam agama dimaksudkan sebagai seluruh aspek yang meliputi keyakinan, teologi, dan juga ibadah-ibadah dalam agama yang khas, seperti shalat, haji, puasa dan dzikir. Aspek material merujuk kepada benda-benda material dalam agama, seperti tempat ibadah, pakaian, kitab suci, benda-benda, manusianya atau penganut agama tertentu dan semua aspek material lainnya. Aspek behavioral merupakan tipe-tipe tingkah laku penganut agama, yang meliputi gaya hidup, sikap, tutur kata, ekspresi kegamaan dan lain sebagainya. Sementara terakhir adalah aspek visual, yang relevan jika kita memahaminya dalam hubungannya dengan perkembangan teknologi. Aspek visual dalam agama adalah segala sistem simbol agama yang terepresentasi dalam ruang publik yang bersifat visual, bisa dilihat, dan kehadirannya membawa makna tertentu. Aspek visual

${ }^{10}$ Sudiarja, A. 2006. Agama (Di Zaman) yang Berubah. Yogyakarta. Kanisius Hal: 32-33

${ }^{11}$ Abdullah, Irwan. 2015. Konstruksi dan Reproduksi Kebudayaan. Yogyakarta. Pustaka Pelajar. hal: 114-116. 
berupa gambar dan juga audio visual, dalam arti video. Perkembangan teknologi internet telah mendorong tumbuhnya aspek visual agama ini ke taraf yang tidak terduga sebelumnya, dan menimbulkan dampak yang juga tidak terduga.

Berbeda dengan tiga aspek sebelumnya, aspek visual tidak mengandung apa-apa selain kedangkalan makna. Visual, baik itu berupa ikon, simbol, maupun indeks selalu terjerat dalam sistem yang disebut oleh Irwan Abdullah, antropolog dari Uniervsitas Gadjah Mada Yogyakarta sebagai mekanisme pendangkalan, yakni sebuah distrosi makna terhadap sesuatu yang diwakilinya. Setiap simbol mewakili sesuatu yang lain, dan sesuatu yang diwakilinya jauh lebih sublim dari yang mewakili. Setiap simbol selalu memiliki sifat memadatkan realitas ke dalam struktur ikonis yang merepresentasikan realitas. ${ }^{12}$ Di sinilah agama visual menempati tempatnya. Visual agama tidak lain dari bentuk gejala dan dinamika baru beragama yang mengkompromikan nilai-nilai agama di satu sisi, dan nilai teknologi dan globalisasi di sisi lain.

\section{Kesimpulan}

Agama tidak hanya sekedar dihayati dan dipraktikkan, atau menjadi rujukan sistem nilai sebagaimana pada masa dulu manusia memaknai agama, tetapi dia juga ditampilkan sedemikian rupa untuk semakin menegaskan realitasnya, di satu sisi, dan juga mendistorsinya, di sisi lain. Faktor teknologi, media, globalisasi dan mobilisasi telah mendekonstruksi aspek-aspek dalam agama itu sendiri. Agama tidak saja ritual, tidak saja memiliki sistem kepercayaan, tidak hanya bagaimana mengatur tingkat laku atau behavioral, tetapi juga tampil dalam wajah-wajah visual di ruang publik. Wajah agama kini benar-benar nyata, menjadi wajah yang tergambar dan bisa dilihat ataupun didengar. Dalam level ini agama telah mengalami pendangkalan, karena visual agama tidak bisa menangkap elan vital agama, tetapi menyajikannya dengan sesuatu sistem simbol yang selalu memilliki dampak pemadatan terhadap realitas. Pada saat bersamaan, agama dianggap memiliki nilai-nilai sebagaimana yang dimiliki oleh barang-barang komoditi ekonomi yang lain, sehingga terjadilah komodifikasi pada saat yang bersamaan.

${ }^{12}$ Abdullah, 2017: 6 
Komodifikasi agama membawa wajah baru agama ke level yang belum pernah dicapai sebelumnya, tepatnya sebelum teknologi itu berkembang seperti saat ini. Dalam inilah agama mengalami visual merchandising. Menjadi tugas pemeluk agama dan para cendikia agar agama tetap dipahami sebagaimana penuntut jalan hidup (way of life) bagi pemeluknya, dan membebaskan agama dari praktik komodifikasi, yang bukannya menambah arti penting agama, tetapi sebaliknya, mendistorsinya menjadi hal-hal yang bersifat pragmatis seperti profit, klaim, dan nafsu pemeluknya. 


\section{Daftar Pustaka}

Tim Penyusun Pusat Bahasa. 2008. Kamus Bahasa Indonesia. Jakarta: Pusat Bahasa.

Sutiono, Rudy Jusup. 2009. Visual Merchandising Attraction. Jakarta: Gramedia Pustaka Utama.

Sugiharto, Bambang. 2000. Wajah Baru Etika dan Agama. Yogyakarta. Kanisius.

Koller, Andreas. 2010. The Public Sphere and Comparative Historical Research: An Introduction. Social Science History Vol. 34, No. 3, In Honor of Charles Tilly (Fall 2010), pp. 261-290.

Einstein, Mara. 2008. Brands of Faith: Marketing Religion in a Commercial Age. Mew York. Routledge.

Hasan, Noor Haidi. 2016. Islam di Kota-kota Menengah di Indonesia: Kelas Menengah, Gaya Hidup, dan Demokrasi. Editor: Gery Klinken dan Ward Berenschot. E. K. M. Masinambow. Jakarta: Yayasan Obor Indonesia.

Ketut Heru Sony Pratama \& Saortua Marbun. 2016. Komodifikasi Penjor sebagai Sarana Persembahyangan Umat Hindu. Jurnal Studi Kultural Sekolah Tinggi Ilmu Ekonomi Triatma Mulya. Volume I. No. 2.

Simanjuntak, Bungaran Antonius. 2016. Tradisi, Agama, Dan Akseptasi Modernisasi Pada Masyarakat Pedesaan Jawa. Jakarta. Yayasan Obor.

Sudiarja, A. 2006. Agama (Di Zaman) yang Berubah. Yogyakarta. Kanisius.

Abdullah, Irwan. 2015. Konstruksi dan Reproduksi Kebudayaan. Yogyakarta. Pustaka Pelajar.

2017. Di bawab Bayang-bayang Media: Kodifikasi, Divergensi, dan Kooptasi Agama pada Era Internet. Disampaikan pada Seminar Nasional Agama, Budaya dan Media: Kontribusi Antropologi Abad 21. Diselenggarakan oleh Program Studi Antropologi Fakultas Ilmu Budaya Universitas Diponegoro, Semarang.

Pawito. 2007. Penelitian Komunikasi Kualitatif. Yogyakarta. LKiS. 